an uncertainly outlined face blends into a landscape annotated like a map. Rocke's drawings dismember the image and evolve into forms that recall elements of asylum life, such as the cells in which patients were held.

Prinzhorn saw the creations of the mentally ill, who were uninfluenced by shifting trends in the art world, as a raw depiction of an individual's condition and a valuable way to externalize the psyche to the outer world. The exhibition is not an enquiry into the origins of mental disorders, but into their lived experience. Noticeable among the contemporary works is the absence of any reference to the brain.

At a time when psychiatry is undergoing huge change - the genetic revision of diagnoses, the search for biological markers and the use of functional magnetic resonance imaging - this exhibition reminds us of the irreplaceable ability of personal narratives to enter the depths of the mind through doors that are not open to biological analysis.

Giovanni Frazzetto is at the BIOS Centre of the London School of Economics, UK. e-mail: g.frazzetto@lse.ac.uk

\title{
Literary inspiration
}

\section{Jorge Luis Borges' writings on memory foretell modern research, Gabriel Kreiman finds.}

$\mathrm{O}$ ne of the most creative literary thinkers of the last century was Argentinian author Jorge Luis Borges (1899-1986). In his stories, Borges stretched the meaning and basic rules of space, time and infinity. He pondered instruments that could view the entire Universe, the effects of allowing one second to instantly become one year, infinite labyrinths and endless cyclic books. Borges was also intrigued by memory, its functions and its malfunctions.

A book in Spanish (English translation pending), Borges y la Memoria (Borges and Memory) by neuroscientist Rodrigo Quian Quiroga, eloquently links Borges' ideas with the latest research on memory. Focusing on the protagonist of Borges' 1942 essay, Funes el Memorioso (Funes the Memorious), and examining real experiments and consequences, Quian Quiroga offers a fascinating account of the connections between science and art.

The scientific study of memory often focuses on how we learn, how information is stored in circuits of neurons and how short-term memories are consolidated into long-term ones. Less attention is paid to the important ability to generalize and to forget. Borges explored both through the fictional character of Funes, who receives a brain injury after falling from a horse.

Because of his prodigious memory, Funes always knows the precise time without having to consult his watch, learns languages after merely checking a dictionary and can enumerate all the people he has ever met. Although these abilities seem admirable, there is a catch. Every leaf of every tree that he has ever seen remains in his mind. It disturbs him that a front view of a face is assigned the same identity as the profile view. He is almost incapable of understanding or creat-

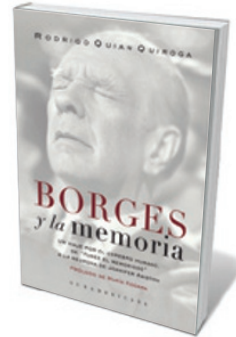

Borges y la Memoria

RODRIGO QUIAN QUIROGA

Sudamericana: 2011 (in Spanish). Ps65 (US\$15) study described patient H. M., who could easily recollect information from before his hippocampal surgery but had difficulty retaining subsequent experiences. He would meet a new person and hold a pleasant conversation, yet the next day he would have no recollection of what the person looked like or what they had spoken about.

Several important investigations ensued. Behavioural studies in rodents and

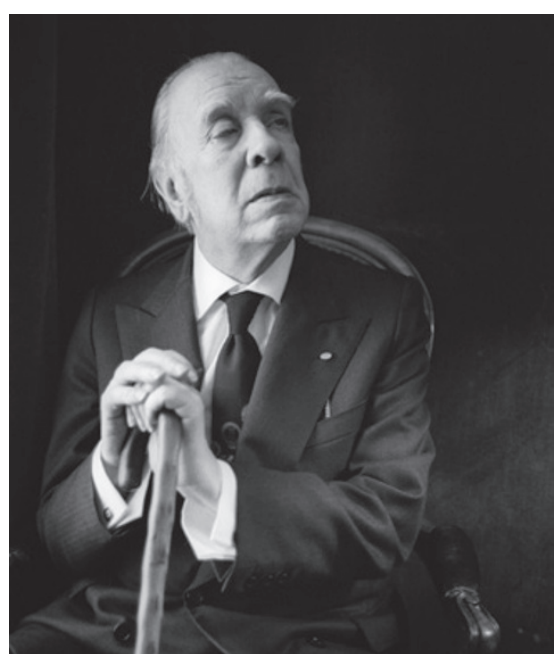

The mind's labyrinth intrigued Jorge Luis Borges. non-human primates characterized the effects of lesions in the medial temporal lobe and confirmed the central role of the hippocampus in learning. Listening in on the activity of neurons by inserting thin needles into rodents' brains revealed that hippocampal neurons can change their connection strengths in ways that correlate with learning and memory formation. Similar recordings in humans uncovered neurons in the hippocampus that showed sparse and invariant responses that are reminiscent of abstract elements of perceptions and memories.

Despite these breakthroughs, our scientific understanding of memory processes is in its infancy. We do not know how the hippocampus and cortical structures communicate to allow memory consolidation; how circuits of neurons store long-term information; whether there are capacity limits to human memory; or how to apply the properties of fault-tolerance, abstraction and speed so nicely implemented by the human brain to the design of other circuits.

Quian Quiroga's thoughtful book reminds us that elucidating the mechanisms that lead to generalization and abstraction constitutes a key step towards characterizing human intelligence. As Borges put it: "To think is to forget a difference, to generalize, to abstract”. .

Gabriel Kreiman is assistant professor in the Departments of Ophthalmology and Neurology at Children's Hospital Boston, Harvard Medical School, Boston, Massachusetts 02115, USA.

e-mail: gabriel.kreiman@tch.harvard.edu

\section{CORRECTION}

Patricia Churchland's review (Nature 475, $35 ; 2011)$ incorrectly stated that huskies run at a pace of more than 5 kilometres (3.2 miles) a minute. The pace should have been '3.2-minute miles'. 